\title{
A FRAMEWORK FOR THE DETAILED FLOOD VULNERABILITY MODELLING OF BUILT CULTURAL HERITAGE
}

\author{
RUI FIGUEIREDO ${ }^{1 *}$, XAVIER ROMÃ̃O ${ }^{1}$ AND ESMERALDA PAUPÉRIO ${ }^{2}$ \\ ${ }^{1}$ CONSTRUCT-LESE, Faculty of Engineering, University of Porto \\ Rua Dr. Roberto Frias, s/n, 4200-465 Porto, Portugal \\ e-mail: \{ruifig, xnr\}@fe.up.pt (*corresponding author) \\ ${ }^{2}$ Construction Institute, Faculty of Engineering, University of Porto \\ Rua Dr. Roberto Frias, s/n, 4200-465 Porto, Portugal \\ e-mail: pauperio@fe.up.pt
}

Keywords: Cultural Heritage, Flood Vulnerability, Flood Risk, Risk Assessment

\begin{abstract}
Flooding is the most common and damaging of natural hazards at global level, and in a context of climate change, flood risk is expected to increase. This has prompted governments and international agencies to adopt measures towards the reduction of flood risk in recent years. Among them is the development of flood risk assessments and flood risk management plans, with particular emphasis on cultural heritage, not only due to its significance for society, but also because of its particularly high vulnerability to natural hazards, including floods. In order to quantify risk and define prioritization and management plans for a given set of cultural heritage assets, vulnerability models that allow estimating and comparing the impacts of floods at an asset-by-asset level are required. However, there is currently a lack of approaches in the literature to achieve this. This study proposes a component-based synthetic modelling framework to perform detailed vulnerability analyses of cultural heritage assets. The framework is illustrated through an application to a Portuguese church.
\end{abstract}

\section{INTRODUCTION}

Flood risk is expected to increase worldwide in the coming decades due to various socio-economic and environmental factors, including climate change. Minimizing flood risk across any given region requires robust risk management decision-making, which must necessarily be supported by risk assessment studies. These combine flood hazard data for a region of interest with information on exposed assets and models of their vulnerability (i.e. the impact they are expected to undergo as a function of flood actions), and allow computing consistent risk metrics.

The socio-cultural importance of cultural heritage calls for particular attention to this asset type in any flood risk management plan. However, at present, there is a lack of methods in the literature to quantify the flood vulnerability of cultural heritage assets, which hampers the development of flood risk assessments, and consequently informed risk management prioritization and optimization of mitigation measures. This gap can be justified by various underlying difficulties. Firstly, cultural heritage assets tend to differ considerably among themselves, precluding the development and application of common vulnerability models to 
portfolios of assets, except in large-scale risk assessments for preliminary screenings of risk. Secondly, empirical approaches commonly adopted for other asset types, such as common residential buildings, are not applicable, because they require datasets of observed damage and/or losses, which are not available for cultural heritage assets. Thirdly, there is no agreed upon method to quantify the value of cultural heritage assets and, consequently, their degree of damage or loss as a result of a disaster $[1,2]$.

This study aims to address the above issues by proposing a framework to model the flood vulnerability of cultural heritage assets, so that this information may be used within risk assessment studies where an asset-by-asset differentiation of risk is required. The proposed approach is based on a component-based synthetic modelling framework, whereby hypothetical flood scenarios are simulated and the corresponding potential overall damage is estimated as the combination of damage to each component of cultural value comprising an asset. The modelling framework is illustrated through an application to a church in Portugal.

\section{METHODOLOGY}

For each cultural heritage located in an area of interest, flood risk is defined as the probability that damage will occur as a result of flooding, and is commonly expressed as a function of hazard, vulnerability, and exposure. Within this conceptual framework, hazard represents the intensities and probabilities of occurrence of flood scenarios, exposure expresses the assets' overall values, and vulnerability links flood intensities to potential impacts. This paper

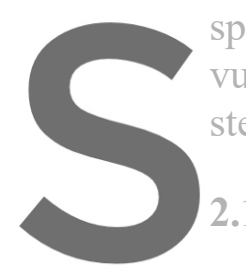
specifically addresses the latter, presenting a methodology for the quantification of the
vulnerability component of risk for cultural heritage assets. The approach is organized into three
steps that are described in the following subsections.
2.1 Surveying and value assessment of exposed components

The specific nature of cultural heritage requires an asset-by-asset characterization of

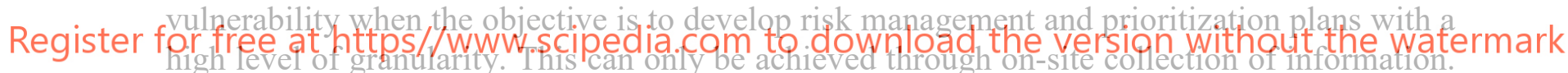
Therefore, the first step of the methodology involves the identification, documentation and value assessment of all the relevant exposed components that comprise a cultural heritage asset and contribute to its overall cultural value. The surveying process should allow collecting the most relevant information for characterizing the flood vulnerability of an asset. Simultaneously, it should also be a simple procedure that can be carried out efficiently without the need to involve significant resources and/or specific engineering skills (to allow surveys to be carried out by local non-technical stakeholders). In this regard, the two fundamental variables that need to be collected are the main material of each component and the height at which it is located.

In order to facilitate the surveying process of a given cultural heritage asset and help ensure that relevant components are not left out, it is useful to establish a taxonomy for such components beforehand. Because this classification scheme could vary significantly between different asset types, specific taxonomies should be defined for each type. For the case of churches, a taxonomy is proposed in Table 1, which was developed to support the application of the framework to the case study described in Section 3, a Portuguese church. The most common material types for each component are also identified to further support the surveying procedure. 
Table 1: Proposed component taxonomy for churches, containing the most relevant components commonly found in Portuguese churches and their respective materials.

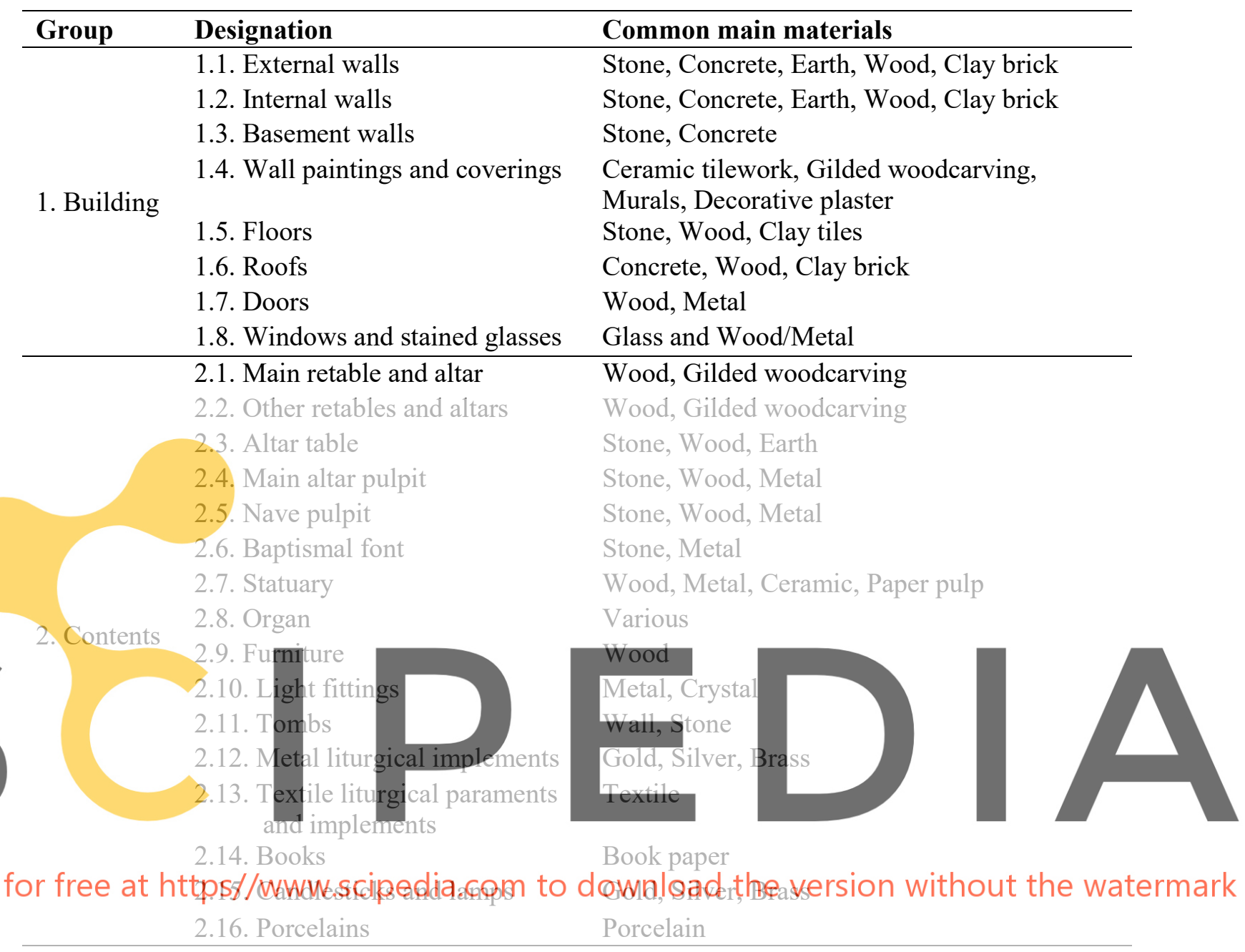

After the component survey, it is then necessary to estimate the value of each of the selected components. Given that such values cannot be expressed in absolute economic terms, within the proposed framework, indices of value for the different components of the cultural heritage asset are defined, which reflect their estimated relative value with respect to the other selected components. It is recommended that at least three levels of significance are adopted:

- a low level, for components that are not unique and that contribute in a limited manner to the overall cultural value of the asset;

- an intermediate level, for unique components that have significant cultural value;

- a high level, for unique components with exceptional cultural value, which are determinant for the overall cultural value of the asset.

In order to expedite the surveying procedure, particularly in situations with a large number of components, it is suggested that only components that can be affected by floods up to a certain return period are documented, and that the relative value of those components with respect to the whole set of components (i.e. floodable and non-floodable) is defined in aggregated terms, based on expert judgement. 


\subsection{Estimation of flood susceptibility for each component}

The susceptibility of each component is defined as the level of impact it is expected to undergo as a result of the action of flooding. In order to estimate the susceptibility of different components, a literature review was carried out in order to characterize the effects of floodwater on certain commonly found materials [3-12], taking the taxonomy shown in Table 1 as a reference. A summary is presented in Table 2 for some materials. Based on this analysis, the susceptibility of each material was translated into a scale of indices, as represented in Figure 1. Note that for each material, besides a base level or range of susceptibility indices (represented by the hatched shapes), there are also higher levels of possible impact that are determined by amplifying factors related, for example, to the material condition, inadequate post-event drying or treatment, or the level of floodwater contamination, according to the descriptions presented in Table 2.

Table 2: Effects of exposure to flood water for some of the most commonly found materials in Portuguese churches.

\begin{tabular}{ll}
\hline Material & Description \\
\hline Stone & - Different types of stone can behave differently under the actions of flooding, \\
depending on their softening coefficient and hydric expansion. & - The susceptibility of most common types of stone to flooding is generally low. \\
- Negative impacts can increase if walls are not properly treated and dried after an \\
event, if they are in poor state of conservation, or due to harsh weather conditions.
\end{tabular}


Table 2: Effects of exposure to flood water for some of the most commonly found materials in Portuguese churches (continued).

\begin{tabular}{|c|c|}
\hline $\begin{array}{l}\text { Paintings on } \\
\text { canvas }\end{array}$ & $\begin{array}{l}\text { - Exposure to water can cause immediate damage to most paintings, as well as } \\
\text { make the artwork more susceptible to short or long-term damage. Appropriate } \\
\text { drying is required to reduce negative impacts. } \\
\text { - Water can lead to flaking and loss of image layers, as well as expansion, } \\
\text { shrinkage and subsequent deformation of painting supports. }\end{array}$ \\
\hline Textiles & $\begin{array}{l}\text { - Textiles can present significant variations that determine if and how they can } \\
\text { be salvaged after a flood. Damaged textiles can present colour change, bleeding } \\
\text { of dyes, shrinkage, watermarks from migrating finishes, and mould. } \\
\text { - Certain contaminants will require textiles to be discarded. }\end{array}$ \\
\hline
\end{tabular}

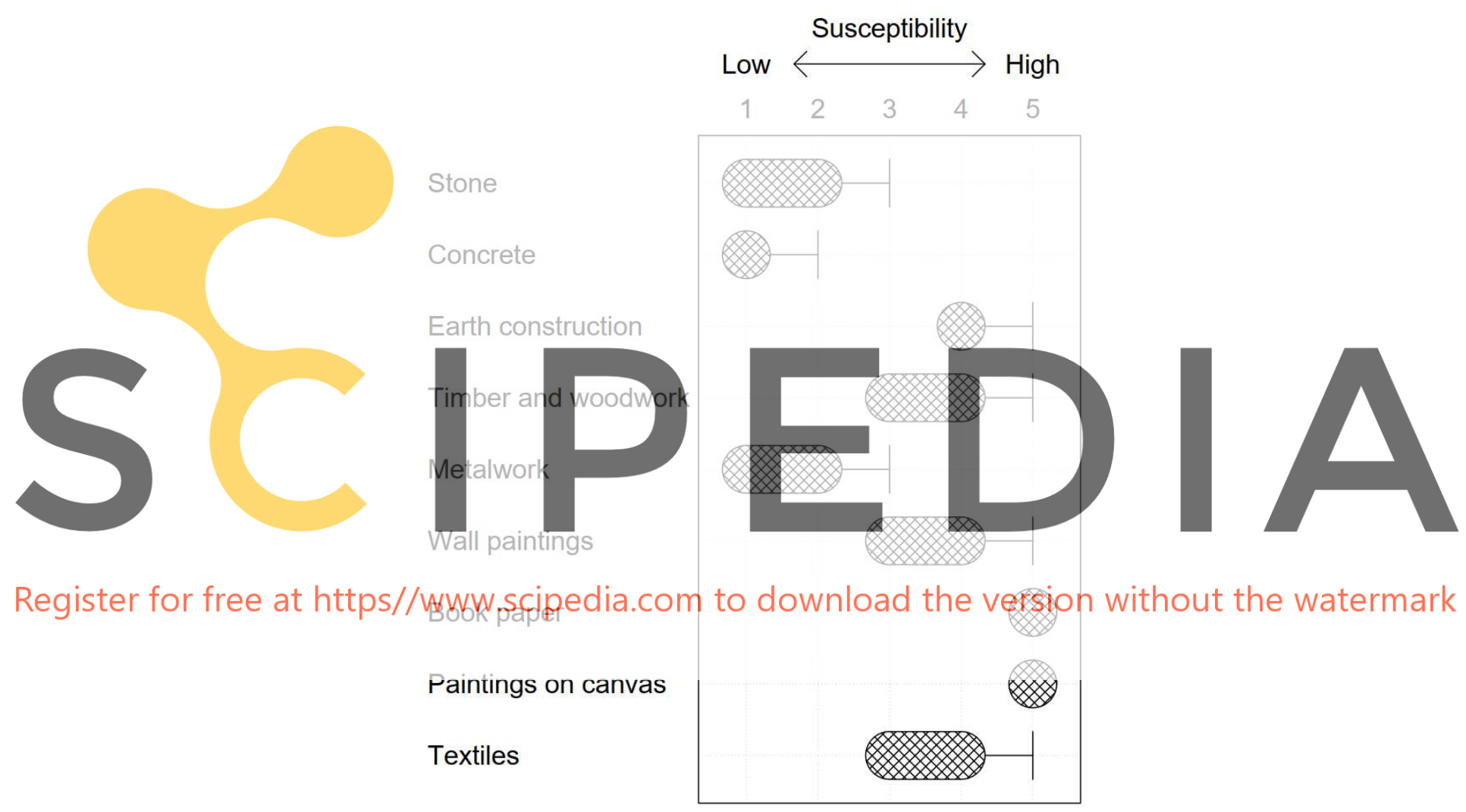

Figure 1: Examples of flood susceptibility indices considered for some materials.

\subsection{Definition of the flood vulnerability function}

The vulnerability function for a cultural heritage asset can then be defined as a function of the value, susceptibility, and elevation of its components. Given that values and impacts cannot be expressed in absolute terms, the vulnerability function should quantify impacts in relative terms, i.e. as a fraction of the overall cultural value of an asset (which should be defined independently of the quantification of vulnerability, based for example on its listed status). In order to achieve this, a normalization of the above indices is required. The value indices of the asset's components should be scaled such that they sum to one. In this way, the resulting values 
will represent the fraction that each component is estimated to contribute to the overall value of the cultural heritage asset. The susceptibility indices should be scaled such that 'no damage' corresponds to 0 , while 'damage that is not fully repairable' corresponds to 1 . The vulnerability function is then obtained through a what-if analysis, based on a simulated step-by-step inundation of the asset, and in the evaluation of the corresponding damage based on the features described before. The level of damage at each step is given by

$$
f(x)=\sum_{i} g(x) v_{i} s_{i}
$$

with

$$
g(x)= \begin{cases}1 & \text { if } x \geq h_{i} \\ 0 & \text { if } x<h_{i}\end{cases}
$$

where $x$ is the water denth, $i$ represents each component of the cultural heritage asset, $h_{i}$ is the height at which the component is located above a reference level (typically the external ground floor level, from which the water depth is also measured), and $v_{i}$ and $h_{i}$ are their value and susceptibility indices, respectively.

\section{CASE STUDY}

\subsection{Description}
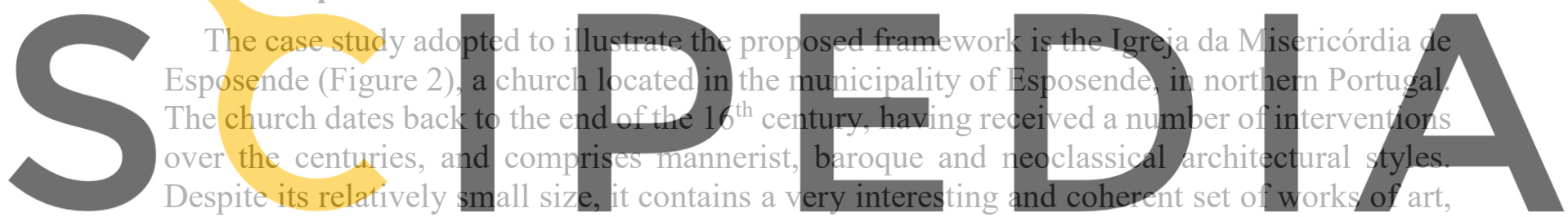
and is listed as a building of public interest $[13,14]$.

Register for free at https//www.scipedia.com to download the version without the watermark

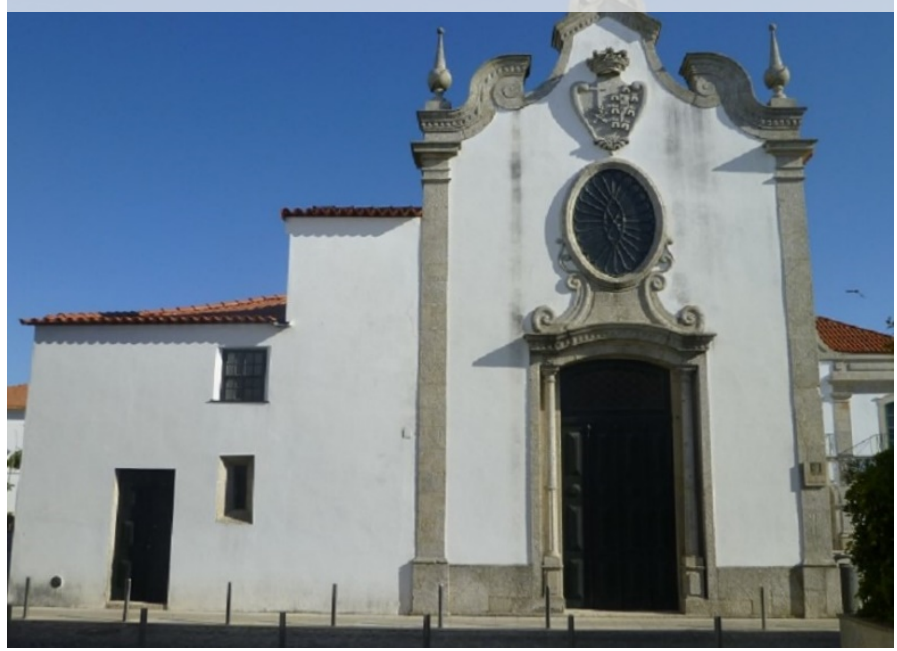

Figure 2: Main façade of the church. 
Based on to the hazard maps developed for Portugal within the scope of the European Floods Directive [15], the church is located within the extents of high-probability flood scenarios, and the water depth associated with an extreme scenario of 1000-year return period (considered herein as the maximum achievable water depth) is $1.38 \mathrm{~m}$ (Figure 3).
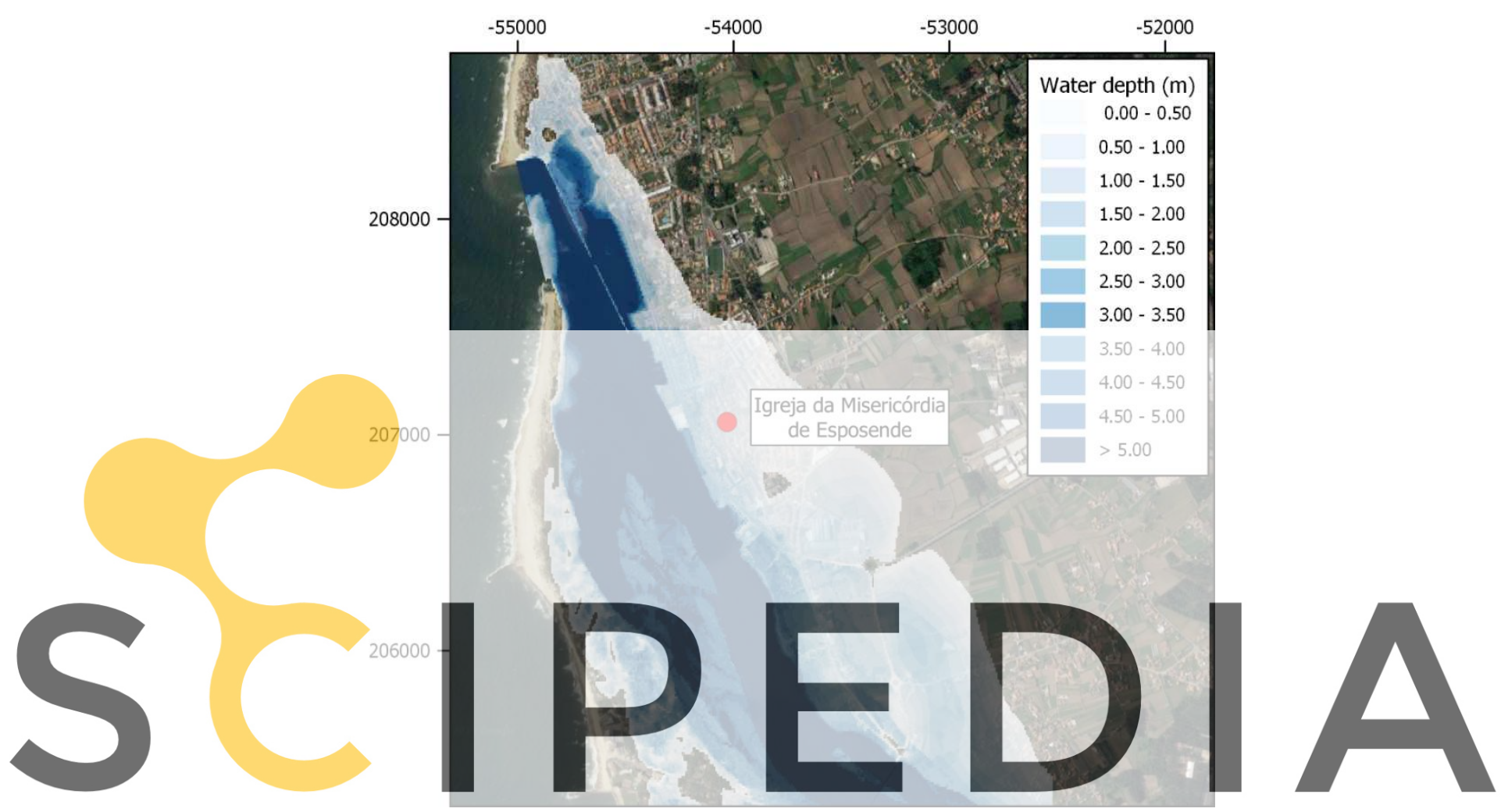

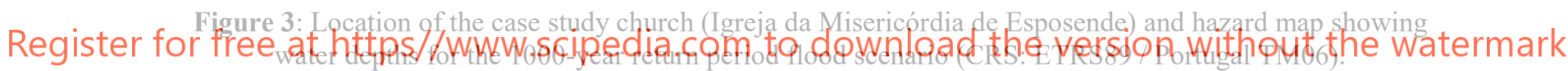

\subsection{Vulnerability assessment results}

The church was surveyed by the authors on 3 January 2020 following the general procedure described in Section 2. A detailed inventory was developed for the ground floor only (shown in Figure 4), given that the uppers floors are above the maximum flood level. Still, the entire church was surveyed in order to establish the relative value of the floodable components.

The inventory comprises both building and contents; it includes a total of 79 components and component assemblies, together with their materials, heights from the reference level, and information on whether they are moveable. The latter allows establishing two separate vulnerability functions that consider scenarios with and without the preventive evacuation of moveable items. Three indices of value (1, 3 and 10) were considered for assets with low, substantial, and exceptional significance, respectively. Table 3 presents the inventory referring to the contents of the main chapel, and a photograph of this part of the church is shown in Figure 5. For brevity, only this part of the inventory is presented herein. Finally, the obtained vulnerability function is presented in Figure 6. 


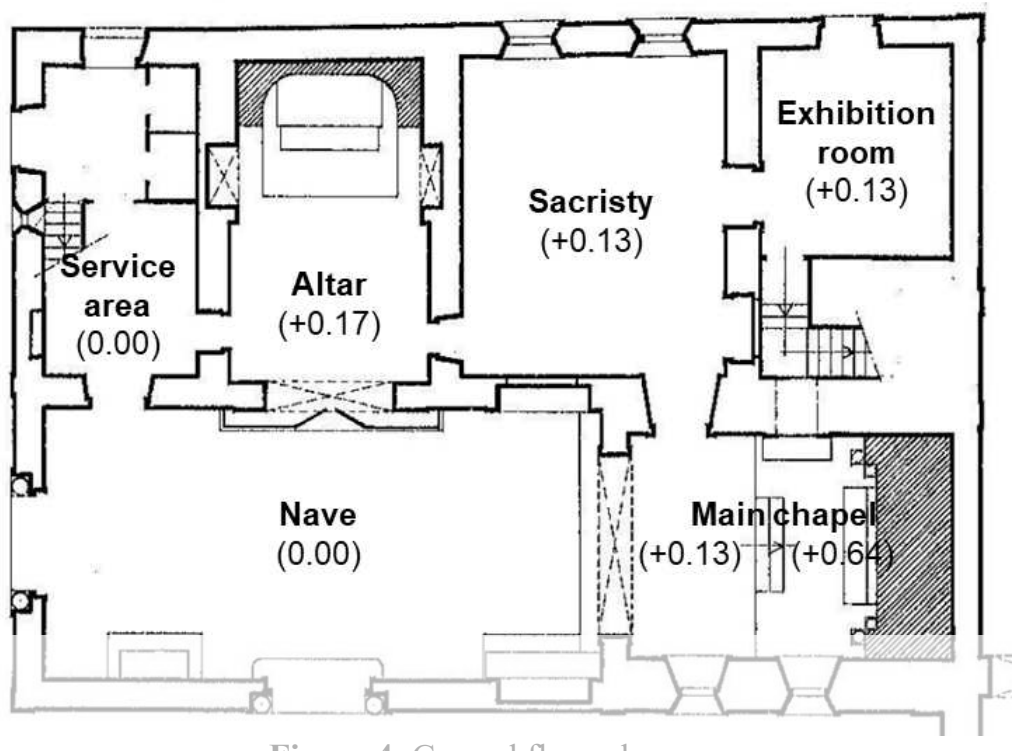

Figure 4: Ground floor plan.

Table 3: Inventory of contents of the main chapel.

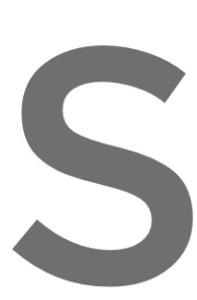

Component

Plinths (set of 2)

Statue

Statue

Kneeling benches

(set of 2)

Altar table
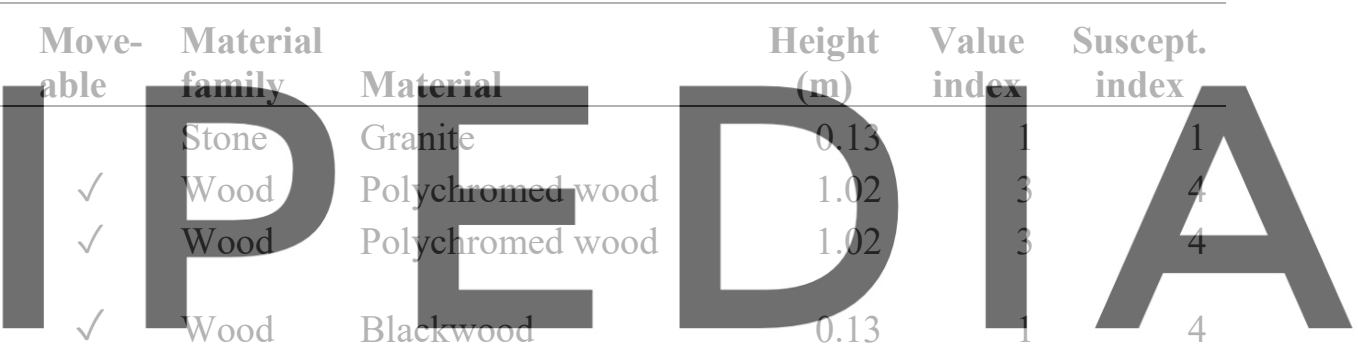

Wood Gilded woodcarving

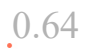

Register for filp

\section{Altar \\ Statue \\ Main altar \\ Main retable \\ Painting}

Candlesticks (set of 2)

Candlesticks (set of 2)

Jugs (set of 2)

Individual benches

(set of 4)

Altar side table

Chair

\section{Wood Gilded woodcarving}

$\checkmark$ Wood Polychromed wood

Wood

Gilded woodcarving

Wood

Gilded woodcarving

Canvas

Painting on canvas

$\checkmark$ Wood Gilded woodcarving

Brass

$\checkmark \quad$ Metal

Porcelain

$\checkmark$ Wood Blackwood

$\checkmark$ Wood

Gilded woodcarving

Upholstered blackwood
1.29

1.64

0.64

0.64

2.49

1.84

1.84

1.84

0.64

0.64

0.64
4 

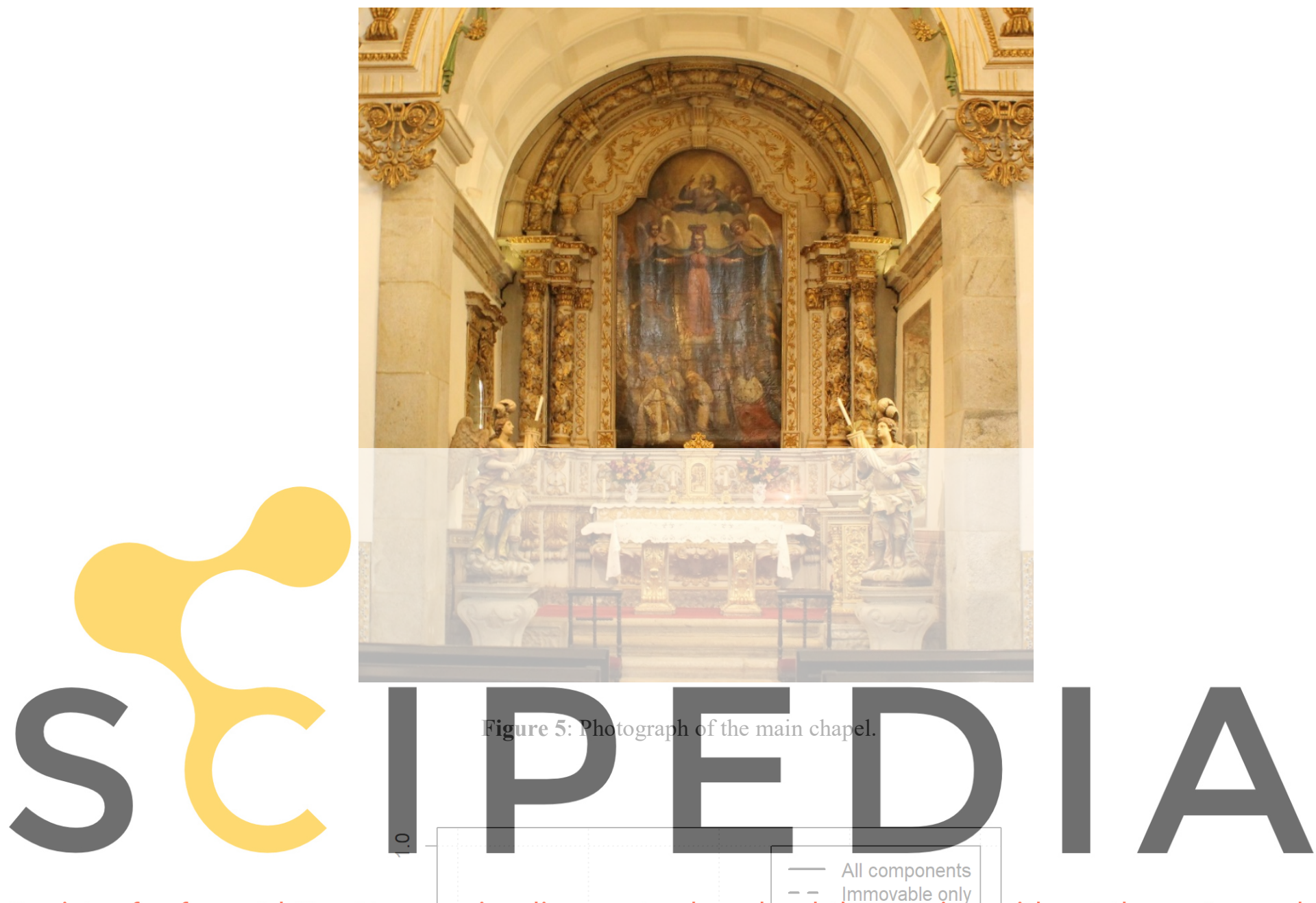

Register for free at https//www.scipedia.com to download the version without the watermark

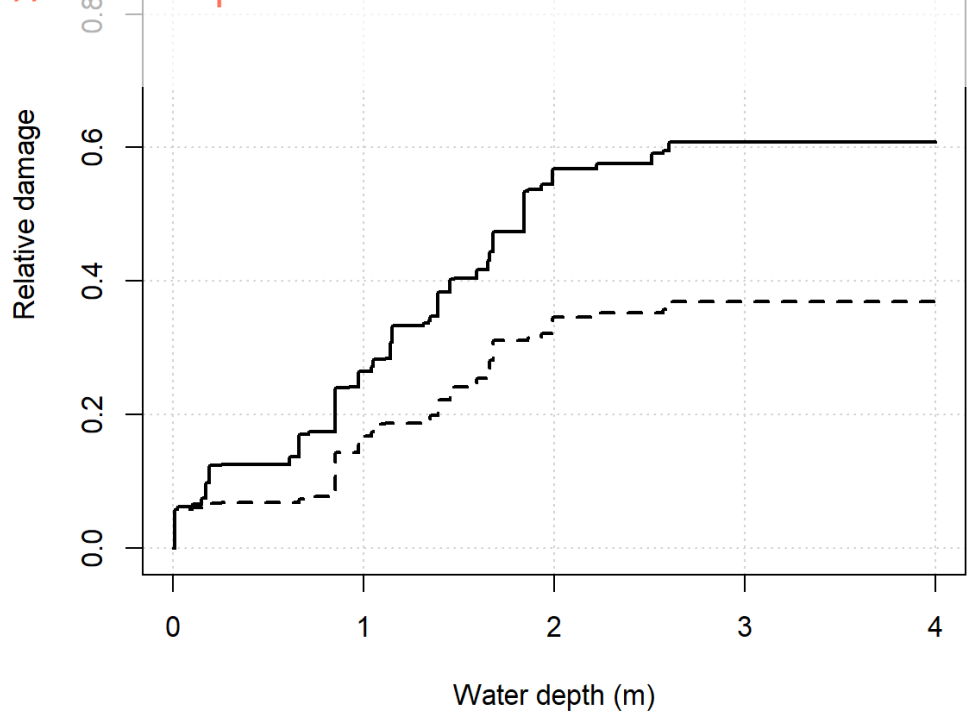

Figure 6: Vulnerability function for Igreja da Misericórdia de Esposende. 


\section{DISCUSSION}

This paper has illustrated a new framework to model the flood vulnerability of cultural heritage assets based on a component-by-component analysis. The main objective of this framework is to provide a vulnerability analysis for risk assessment studies that aim to determine and compare levels of risk among cultural heritage assets, supporting the implementation of risk management plans at a detailed level. Although this inevitably requires site-specific surveying, the framework has been designed to achieve an adequate balance between simplicity and accuracy. Nevertheless, the framework may still be expanded to account for other flood properties besides water depth, such as flood duration and flow velocity, which may be relevant for certain building components.

In this study, the proposed vulnerability modelling framework was showcased for a church in northern Portugal, demonstrating its applicability. Further research will include applications to other churches in order to perform a comparative analysis of risk levels. This is also expected to provide insights about the practicability of aggregating asset-specific vulnerability functions in order to derive functions for asset classes with similar characteristics and quantify the associated uncertainty.

Acknowledgements. The authors would like to thank Câmara Municipal de Esposende and Santa Casa da Misericórdia de Esposende for their availability. This work was financially supported by: Project POCI-01-0145-FEDER-030469 - RIACT - Risk Indicators for the Analysis of Cultural heritage under Threat, funded by FEDER through COMPETE2020 Programa Operacional through FCT - Fund UIDB/04708/2020 of by national funds through FCT/MCTES (PIDDAC)

\section{by nationat for}

Register farfree latibtos//www.scipedia.com to download the version without the watermark

[1] Figueiredo, R., Romão, X., Paupério, E., Flood risk assessment of cultural heritage at large spatial scales: Framework and application to mainland Portugal. J. Cult. Herit. 2019.

[2] Stephenson, V., D’Ayala, D., A new approach to flood vulnerability assessment for historic buildings in England. Nat. Hazards Earth Syst. Sci. 2014, 14, 1035-1048.

[3] Siedel, H., Historic building stones and flooding: Changes of physical properties due to water saturation. J. Perform. Constr. Facil. 2010, 24, 452-461.

[4] English Heritage, Flooding and Historic Buildings. 2015.

[5] Štulc, J., The 2002 Floods in the Czech Republic and their Impact on Built Heritage. Herit. Risk 2008, 133-138.

[6] Drdácký, M.F., Flood Damage to Historic Buildings and Structures. J. Perform. Constr. Facil. 2010, 24, 439-445.

[7] Boinas Dias, A.R., Análise de risco de cheia: desenvolvimento de um modelo aplicado ao Património Nacional, Universidade do Porto, 2014.

[8] Northeast Document Conservation Center, Emergency Salvage of Wet Books and 
Records. 2019.

[9] Ray, E., The Prague library floods of 2002: Crisis and experimentation. Libr. Cult. Rec. 2006, 41, 381-391.

[10] Klempan, B., Emergency Treatment of Water-damaged Paintings on Canvas - Canadian Conservation Institute (CCI) Notes 10/5, 2017.

[11] Braaten, A., Flood-damaged Textiles: What to Salvage and How to Clean, North Dakota State University, 2009.

[12] Kirby, S., Hammett, W., Cleaning Flooded Upholstered Furniture, Curtains, Bedding, Table Linens and Other Household Textiles, North Carolina State University, 2014.

[13] Afonso, J.F., Martins, S., Rodrigues, R., Calvo, A., et al., Uma Confraria do Mar: A Misericórdia de Esposende entre os Séculos XVI e XIX, Câmara Municipal de Esposende / Santa Casa da Misericórdia de Esposende, 2014.

[14] Direção-Geral do Património Cultural, SIPA - Sistema de Informação para o Património Arquitetónico. 2019.

[15] Brandão, C., Saramago, M.M., Ferreira, T., Cunha, S., et al., Elaboração de Cartografia Especifica sobre Risco de Inundação para Portugal Continental. 2014. 